\title{
Evaluation of a Thermochromic Liquid Crystal for Use as a Temperature Sensor for Components of Electrical Systems
}

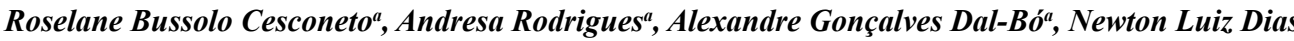 \\ Filho $^{a}$, Marcio Roberto da Rocha ${ }^{a}$, Tiago Elias Allievi Frizon ${ }^{a, b *}$ \\ a Programa de Pós-Graduação em Ciência e Engenharia de Materiais - PPGCEM, Universidade do \\ Extremo Sul Catarinense, 88806-000, Criciúma - SC, Brasil \\ ${ }^{b}$ Universidade Federal de Santa Catarina - UFSC, Campus Araranguá, SC, Brasil.
}

Received: September 23, 2016; Revised: April 23, 2017; Accepted: May 01, 2017

\begin{abstract}
Connectors used in electrical power distribution systems should allow the passage of electricity continuously and without interruption. However, this does not always occur due to failure caused by improper assembly and/or corrosion of the materials employed, which reflects the quality of service. Notable among the new detection technologies that have been studied to facilitate the identification of defects is the use of thermochromic materials, which allow the easy identification of "hot spots", without the need for specialized equipment and personnel. In this context, in this study, the performance of a thermochromic liquid crystal was evaluated with the aim of developing a temperature sensor for connectors used in electrical power distribution networks. For the evaluation of the performance, thermal and ultraviolet radiation degradation tests were conducted, as well as analysis using spectroscopic (FTIR, FTIR-HATR, UV-Vis, 1H NMR) and thermal (DSC, PLM) techniques. The results indicated that the liquid crystal and the associated components showed no degradation under the test conditions, as well as a good color stability was observed, verifying the viability of the use of these materials for the construction of a temperature sensor. A field test was performed with the devices and was effective for the suggested application.
\end{abstract}

Keywords: Temperature sensor. Electrical connector. Liquid Crystal. Thermochromic.

\section{Introduction}

Systems for the distribution of electrical power rely on several components, which perform important roles in relation to the continuous passage of electric current through contact surfaces, without interruptions, and the reduction of losses ${ }^{1}$. These systems involve electrical connections between circuits, equipment and extensions. Wedge-type connectors are installed between aluminum or copper wires and cables using appropriate impact tools, with the detonation of explosive charge cartridges ${ }^{2}$.

Poor tool handling, resulting in bad contacts, and corrosion processes can cause overheating in the connections, which can lead to increases in the losses and interruption of the electrical power supply. It can also adversely affect the quality of the service provided by the power distribution companies in relation to their adherence to the standards and parameters established by the Brazilian Electricity Regulatory Agency (Agência Nacional de Energia Elétrica, ANEEL) ${ }^{3}$, which can incur heavy fines ${ }^{1,4,5}$. Thus, the identification of overheating in the components of electrical systems is of great interest to power distribution companies, since possible failures and interruptions in the electrical power supply can be identified ${ }^{1,4}$.

\footnotetext{
* e-mail: tiagofrizon@gmail.com
}

The detection of overheating in the components of an electrical system is currently carried out based on different signal transmission mechanisms ${ }^{6,7}$. However, this approach has limitations which can lead to an incorrect diagnosis of the problem or inhibit the detection of a fault, and the method is also often very costly to implement. Contact sensors, thermocouples, resistance temperature detectors and thermometers collect and transfer data obtained in inspections to a data acquisition and processing center. This involves the use of extensive wiring ${ }^{1}$, equipment, software programs and specialized personnel to interpret the data. Thermal imagers, which measure the emitted infrared radiation, are dependent on in loco parameters of regulation and thus certain skills are required on the part of the operator. Also, specialized personnel are needed to interpret the data obtained, and the weather conditions need to be considered, since on very bright or rainy days the correct identification of a faulty component is hindered.

New technologies have been developed and used to monitor and detect hot spots, notably the use of sensors which employ thermo-sensitive materials, with chromic phenomena, since they produce an optical response which is easy observed ${ }^{8,10}$. In this respect, the use of sensors based on organic materials provides an alternative, since their color changes when they are submitted to temperature variations, 
enabling the detection of faulty components as a result. Among these materials, cholesteric liquid crystals are widely used, as they respond easily to temperature changes ${ }^{11}$ and thus make it possible to estimate temperature ${ }^{12}$. The chiral molecules that form the cholesteric liquid crystals, pack to minimize unfavorable steric interactions, forming an optically active helical macrostructure. When the pitch propeller formed by the orientational ordering of the molecules is comparable to the visible light range, the helical phase will scatter or reflect iridescent light $^{13}$.

This fact is related to the size of the helical pitch, which is very sensitive to temperature variations. The size of the pitch is of the order of a few angstroms, thus having the same order of magnitude as the wavelength of the visible electromagnetic spectrum ${ }^{14}$. Therefore, the color of the scattered light also depends on the ambient temperature, consequently being able to produce a thermochromic effect when the helical pitch is comparable to the light wavelength ${ }^{15}$.

Due to the properties exhibited by cholesteric liquid crystal materials, they can be applied in many different ways, since technological applications such as computer displays, cell phones, paints and adhesives; also can be applied as thermal sensors in industrial engines, electric wires, food and beverage packing ${ }^{16}$.

In this context, the aim of this study was to develop and evaluate a temperature sensor for the visual detection of overheating in components of electrical power networks. The sensor is versatile in terms of both application and inspection, does not require the use of optical equipment (naked eye detection), and allows easy interpretation of the results ${ }^{9,10}$.

The identification is easy due to the sensitivity of some cholesteric liquid crystal, leading to a color change according to the temperature. The sensor can be applied to a wide range of components which can undergo overheating, for instance, connectors, switch disconnector, distribution and power cables and electrical circuit boards.

\section{Materials and Methods}

A thermochromic liquid crystal (Cholesteryl Perlagonate - purchased from Sigma-Aldrich (St. Louis, MO, USA)) was melted on Petri dishes on a plate and cooled to room temperature, forming a layer with an average thickness of 0.37 $\mathrm{mm}$. To provide protection against ultraviolet (UV) radiation, the dishes were covered with a self-adhesive polymeric film of colorless laminated polyester, manufactured by Insulglass ${ }^{\circledR}$, with dimensions of $120 \mathrm{~mm}$ x $30 \mathrm{~mm}$ x $0.04 \mathrm{~mm}$ (length $\mathrm{x}$ width $\mathrm{x}$ thickness). The above-mentioned materials were used to prepare prototypes of the temperature sensor with a recipient base comprised of a 1090 aluminum plate, with dimensions of $50 \mathrm{~mm} \times 50 \mathrm{~mm} \times 0.4 \mathrm{~mm}$ (length $\mathrm{x}$ width $\mathrm{x}$ thickness), in which a central circular cavity was excavated, with a diameter of $30 \mathrm{~mm}$ and depth of $2 \mathrm{~mm}$. A black coating was applied to the cavity using carbon originating from the

combustion of butane gas, in order to provide color contrast in relation to the LC, and a layer of bi-component (acrylic/ aliphatic) polyurethane varnish (WEGTHANE ONA 501), manufactured by WEG, was applied over the LC and cured for $24 \mathrm{~h}$. The cavity was filled in with molten LC and the prototype surface was covered with polymeric film molded with a heat gun. Figure 1 shows the assembly scheme for the temperature sensor prototype. The LC, the protective polymeric film and the temperature sensor prototypes were tested under exposure to artificial conditions in a thermal chamber and in two UV radiation chambers for $1000 \mathrm{~h}$. In the thermal chamber, manufactured by Biopar Equipamentos Eletrônicos Ltda (model S22 SD), the LC deposited on Petri dishes and samples of the protective polymeric film were tested at $50 \pm 2{ }^{\circ} \mathrm{C}$. This temperature was based on data for the highest temperature recorded in 2014 at the weather station of Epagri/Iparque/UNESC ${ }^{17}$. The same chamber was later used to test the temperature sensor prototypes at $78 \pm 2{ }^{\circ} \mathrm{C}$. The UV radiation chamber contained four 15 W tubular fluorescent bulbs manufactured by Glight. Two of these bulbs emitted UV-A radiation at a wavelength of $365 \mathrm{~nm}$ and two emitted UV-B radiation at $312 \mathrm{~nm}$, with a radiation intensity of $0.435 \mathrm{~mW} / \mathrm{cm}^{2}$. The chamber was not cooled and the heating generated by the bulbs reached $45 \pm 2{ }^{\circ} \mathrm{C}$. In another chamber, equipped with a cooling device, six Philips bulbs (model Actinic BL) were used, which emitted UVA radiation at a wavelength of $330 \mathrm{~nm}$, with a radiation intensity of $2.01 \mathrm{~mW} / \mathrm{cm}^{2}$. The radiation measurements were recorded in the chambers with a digital UV measurement device manufactured by Instrutherm (model MRUR-202). The chamber with four bulbs reproduced artificially a $144 \%$ incidence of UV-A and UV-B and the second chamber reproduced $824 \%$ of UV-A, based on data recorded at the weather station of Epagri/Iparque/UNESC between January and December 2014; with a daily average of $13 \mathrm{~h}$ of radiation ${ }^{11}$.

Fourier transform infrared (FTIR) spectroscopy analysis was carried out using a Shimadzu spectrometer (model IRAffinity-1S), with 20 scans, $2 \mathrm{~cm}^{-1}$ resolution and 4000

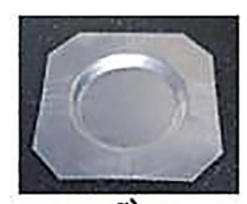

a)

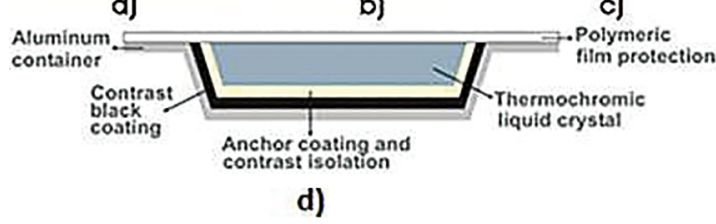

Figure 1. Photographs showing the assembly of the temperature sensor prototype: (a) empty cavity, (b) cavity with black background, and (c) LC at room temperature. (d) Schematic of the temperature sensor prototype (central longitudinal cross section). 
to $600 \mathrm{~cm}^{-1}$ wavelength. The LC samples were analyzed in transmittance mode in sodium chloride windows and samples of the protective polymeric film were analyzed using the horizontal attenuated total reflectance (HATR) technique, in zinc selenide ( $\mathrm{ZnSe})$. Hydrogen nuclear magnetic resonance ( $\left.{ }^{1} H N M R\right)$ spectroscopy analysis of the LC samples solubilized in deuterated chloroform $\left(\mathrm{CDCl}_{3}\right)$ was carried out on an instrument manufactured by Oxford Instruments, operating at $60 \mathrm{MHz}$. A Shimadzu UV-Vis spectrophotometer (model UV-1800), with a scanning from 600 to $200 \mathrm{~nm}$, was used to analyze the LC samples in $9.5 \times 10^{-3}$ molar (M) solutions in dichloromethane $\left(\mathrm{CH}_{2} \mathrm{Cl}_{2}\right)$, in quartz cuvettes with a $10-\mathrm{mm}$ optical path. The samples of the protective polymeric film were attached directly to the cuvette holder. The LC were analyzed by differential scanning calorimetry (DSC) using a TA Instruments calorimeter, (model DSC Q20), under a nitrogen flow of $70 \mathrm{ml} \cdot \mathrm{min}^{-1}$, with heating from $25^{\circ} \mathrm{C}$ to 110 ${ }^{\circ} \mathrm{C}$ at a rate of $10^{\circ} \mathrm{C} / \mathrm{min}$, keeping a constant temperature of $110{ }^{\circ} \mathrm{C}$ for $3 \mathrm{~min}$ followed by cooling to $25^{\circ} \mathrm{C}$. The second heating and cooling run was carried out with the same temperature intervals at a rate of $5^{\circ} \mathrm{C} / \mathrm{min}$. Images of the LC textures were obtained using polarized light microscopy (PLM) with the aid of a Zeiss optical microscope (model Z1) with magnifications of $20 \mathrm{X}$ and with heating from 20 to $110^{\circ} \mathrm{C}$ at a rate of $5{ }^{\circ} \mathrm{C} / \mathrm{min}$ followed by cooling to 20 ${ }^{\circ} \mathrm{C}$ at the same rate. The evaluation of the stability of the temperature at which the color of the LC changed, using the prototypes tested, was carried out applying heating and cooling on a plate and monitoring the temperature with an infrared thermometer. The responses obtained in the analysis of the test specimens were compared to those of the materials without exposure to the test conditions.

The evaluation of the functionality of the temperature sensor in a wedge-type connector was carried out. A simulation of the service conditions was performed with heating and cooling on a heating plate, using an infrared thermometer to monitor the color change according to the temperature.

\section{Results and Discussion}

\subsection{Spectroscopic characterization}

\subsubsection{Fourier transform infrared spectroscopy}

The spectra obtained in the FTIR analysis of LC sample are given in Figure 2, where it can be observed that the characteristic bands obtained for this compound are in agreement with reports in the literature ${ }^{18}$. An intense band at $1735 \mathrm{~cm}^{-1}$ corresponds to the bond stretching vibrations of the carboxyl groups $(\mathrm{C}=\mathrm{O})$ and a set of bands at 2952 to $2852 \mathrm{~cm}^{-1}$ is associated with the stretching vibrations of the bond between the aliphatic carbon and hydrogen $(\mathrm{C}-\mathrm{H})$. The spectra for the LC sample exposed to the test conditions, a)

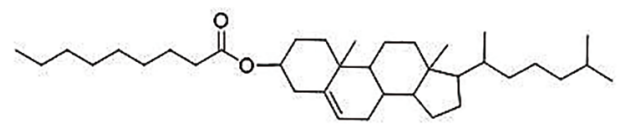

b)

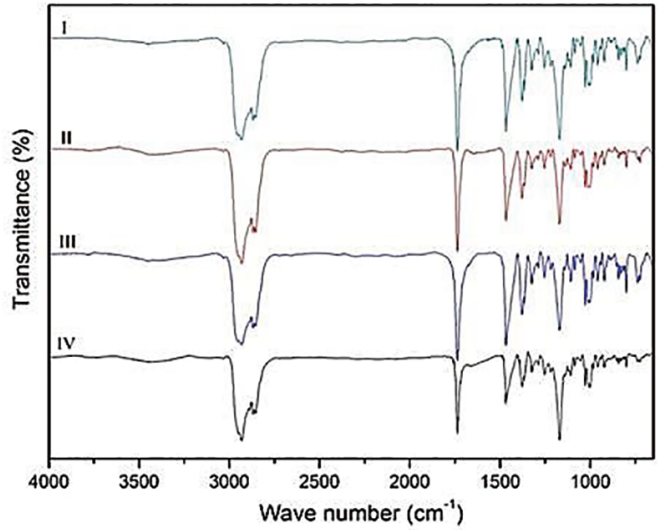

Figure 2. a) Structure of the Liquid Crystal - Cholesteryl Perlagonate; b) FTIR spectra for LC: I) without exposure; II) exposure in UV-A radiation chamber with cooling for $1000 \mathrm{~h}$; III) exposure in UV-A and UV-B radiation chamber without cooling for $1000 \mathrm{~h}$; IV) exposure in thermal chamber for $1000 \mathrm{~h}$.

thermal, UVA and UVB for $1000 \mathrm{~h}$ (Figure 2 II, III and IV) do not show significant changes in comparison to the spectrum of the LC without exposure (Figure 2 I).

\subsubsection{Hydrogen Nuclear Magnetic Resonance}

The ${ }^{1} \mathrm{H}$ NMR spectra for the $\mathrm{LC}$ without exposure and for the samples originating from the Petri dishes exposed to the tests for $1000 \mathrm{~h}$ showed a set of signals, as seen in Figure 3. At 0.30 to $2.50 \mathrm{ppm}$ (represented by a), there is a signal with an area relating to 60 hydrogens, corresponding to the aliphatic part. A signal at $4.59 \mathrm{ppm}$ relates to a hydrogen (represented by $\mathbf{b}$ ) neighboring an oxygen atom of the C-O bond of the $\mathrm{sp}^{3}$ carbon of the molecule.

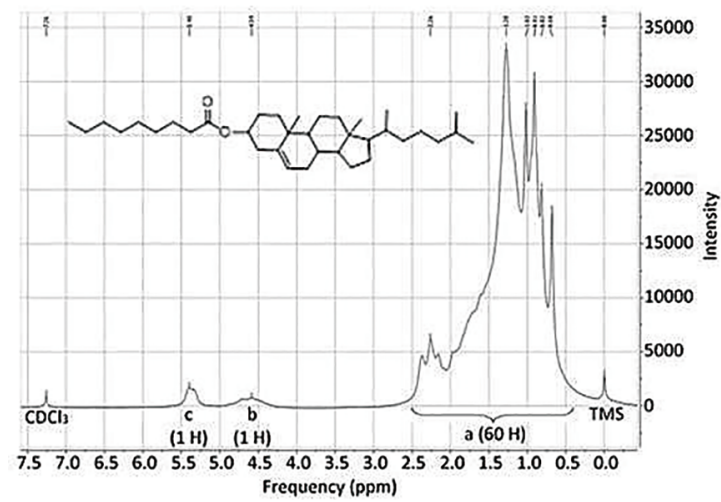

Figure 3. $1 \mathrm{H}$ NMR spectra for $\mathrm{LC}$ sample in $\mathrm{CDCl} 3$. 
A signal was observed at $5.37 \mathrm{ppm}$, which corresponds to the hydrogen (represented by c) in the double bond of cyclohexane. The signals at 0.0 and $7.25 \mathrm{ppm}$ relate, respectively, to the solvents tetramethylsilane (TMS) and deuterated chloroform $\left(\mathrm{CDCl}_{3}\right)$ used in the analysis. No shift in the signal related to the hydrogen was observed and the appearance new signals was not noted, demonstrating the stability of the LC under the conditions analyzed.

\subsubsection{UV-Visible spectroscopy}

The normalized UV Vis spectra show the same maximum intensities and baselines, as shown in Figure 4.

The spectra show a maximum absorption band at 227 $\mathrm{nm}$ with a low molar absorption coefficient $(\varepsilon), 81.4 \mathrm{~L}$. $\mathrm{mol}^{-1} \mathrm{~cm}^{-1}$, which corresponds to a $\mathrm{n} \rightarrow \pi^{*}$ transition of the carbonyl group. In the spectra of Figure 4 a slight broadening appear but no significant changes in the LC samples exposed to tests were observed in comparison to the samples without exposure (represented by $0 \mathrm{~h}$ in Figure 4). A slight yellowing was observed during the longer exposure, but did not show significance through the analysis of the FTIR and NMR spectra performed. In this way, does not present degradation product. However, the liquid crystal will still be protected by a film with UV filter, increasing the photochemical stability of the compound. The results also show that the maximum absorption band of the compound is in the UV-C region and, according to the literature, this radiation does not normally reach the surface of the earth, since it is blocked by the ozone layer ${ }^{19,20}$, and when it does its percentage is low ${ }^{21}$. This favors the use of the LC outdoors, as in the case of temperature sensors used to identify hot spots in electrical connectors.

\subsubsection{Differential scanning calorimetry}

Figure 5 shows the DSC thermogram for the LC without exposure to the tests. In the heating process (lower curve) two endothermic events are observed: a more pronounced peak corresponding to the transformation of the solid phase to the liquid crystal mesophase and another peak at a higher temperature corresponding to the transformation of the mesophase to an isotropic liquid phase.

In the cooling process (upper curve of Figure 5), from isotropic phase, two exothermic events are observed. The first peak corresponds to the transformation of the isotropic phase to the liquid crystal mesophase and the second peak corresponds to a transition from the liquid crystal phase to a solid phase. Table 1 shows the values obtained for the temperatures and variations in enthalpy in the DSC analysis for the LC, under the same conditions of analysis, according to type of sample and the exposure.

A comparative analysis of the values given in Table 1 shows that significant changes in the temperature and enthalpy values for the LC samples exposed to the test conditions did not occur in relation to the unexposed specimens. This suggests that new compounds were not formed, demonstrating the stability of the LC under the test conditions.

\subsubsection{Polarized light microscopy}

The textures observed in the PLM analysis of the LC samples exposed to the test conditions for $1000 \mathrm{~h}$ are the same as those observed for the LC without exposure (Figure 6). Changes in terms of the phase transition temperatures, the formation of a mesophase and fusion were not observed.

It was also observed that all samples melted completely, indicating there was no occurrence of degradation products under the tested conditions.

Based on the LC results obtained from the spectroscopic and thermal methods applied and also the considerations presented herein, the use of the $\mathrm{LC}$ as a temperature sensor is viable since it showed good thermal and chemical stability under the conditions tested.

\subsection{Polymeric film for UV protection}

\subsubsection{Fourier transform infrared (FTIR) spectroscopy}

The spectra corresponding to samples of the polymeric film for UV protection analyzed by FTIR using the HATR method are given in Figure 7. The set of bands observed on

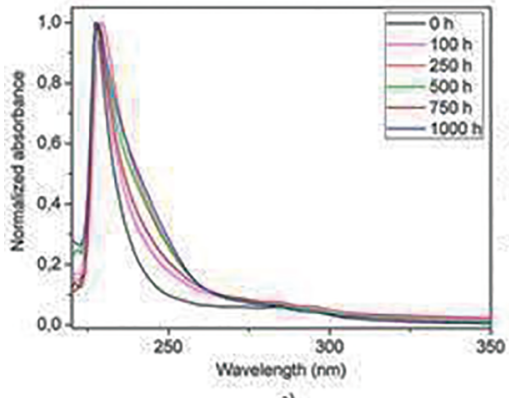

a)

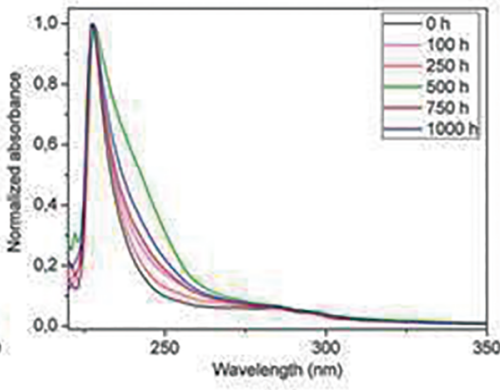

b)

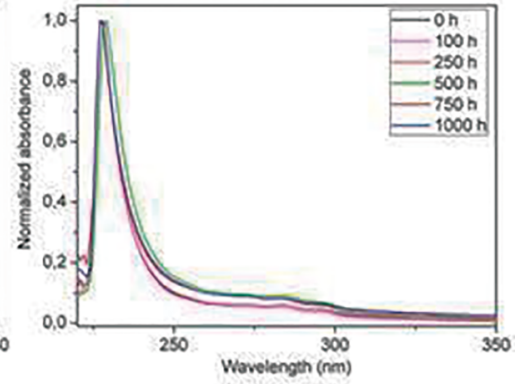

c)

Figure 4. UV-Vis spectra for $\mathrm{LC}$ in $9.5 \times 10-3 \mathrm{M} \mathrm{CH} 2 \mathrm{Cl} 2$ solution according to the exposure time: a) exposure in UV-A radiation chamber with cooling; b) exposure in UV-A and UV-B radiation chamber without cooling; c) exposure in thermal chamber. 


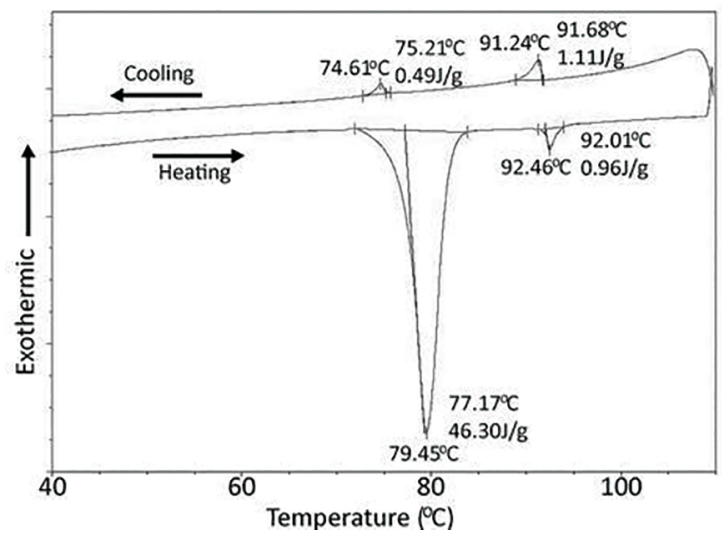

Figure 5. DSC thermogram of the second heating-cooling run with a heating rate of $5^{\circ} \mathrm{C} / \mathrm{min}$ for $\mathrm{LC}$ without exposure to the test conditions.

Table 1. Values determined for the temperature $(\mathrm{T})$ and variation in enthalpy $(\Delta \mathrm{H})$ by DSC in the second heating-cooling run for LC without exposure and samples exposed to the respective test conditions for $1000 \mathrm{~h}$.

\begin{tabular}{lcc}
\hline \multirow{2}{*}{ Type of exposure } & Heating & Cooling \\
& $\mathrm{T}\left({ }^{\circ} \mathrm{C}\right)(\Delta \mathrm{H}(\mathrm{J} / \mathrm{g}))$ & $\mathrm{T}\left({ }^{\circ} \mathrm{C}\right)(\Delta \mathrm{H}(\mathrm{J} / \mathrm{g}))$ \\
\hline \multirow{2}{*}{ Without exposure } & $\mathrm{Cr} 79.45(46.30)$ & Iso $91.24(1.11) \mathrm{LC}$ \\
& $\mathrm{LC} 92.46(0.95)$ Iso & $74.61(0.49) \mathrm{Cr}$ \\
UV-A & $\mathrm{Cr} 79.45(46.34)$ & Iso $91.24(1.30) \mathrm{LC}$ \\
& LC 92.46(1.09) Iso & $74.61(0.47) \mathrm{Cr}$ \\
UV-A + UV-B & Cr 79.44(46.98) & Iso 91.23(1.35) LC \\
& LC 92.48(1.11) Iso & $74.60(0.44) \mathrm{Cr}$ \\
Thermal & Cr 79.70(48.09) & Iso 91.13(1.11) LC \\
& LC 92.57(0.90) Iso & $74.41(0.41) \mathrm{Cr}$ \\
\hline
\end{tabular}

$\overline{\mathrm{Cr}}=$ crystal; $\mathrm{LC}=$ liquid crystal mesophase; Iso = isotropic
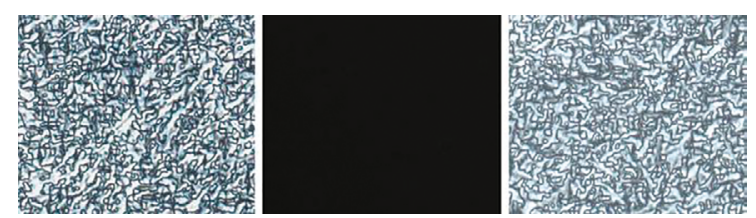

Figure 6. LC textures observed by PLM: (a) on heating; (b) isotropic and (c) on cooling.

the spectra suggests the presence of ester groups. The band at $1726 \mathrm{~cm}^{-1}$ is attributed to the $\mathrm{C}=\mathrm{O}$ bond stretching of the ester groups and the multiple absorption bands at 1250-1050 are attributed to the stretching vibrations of -COO-. The intense band at $720 \mathrm{~cm}^{-1}$ is identified as angular deformations of $\mathrm{CH}_{2}$, which suggests the presence of an $\operatorname{ester}^{22}$. The bands at 2960,2930 and $2860 \mathrm{~cm}^{-1}$ refer to C-H bond stretching of the aliphatic groups, bands at 1630,1450 and $1410 \mathrm{~cm}^{-1}$ can be attributed to the stretching of the aromatic ring and the band at $870 \mathrm{~cm}^{-1}$ to the deformation of the $\mathrm{C}-\mathrm{H}$ bond of the two hydrogen atoms adjacent to the aromatic ring ${ }^{20}$. The band at $3485 \mathrm{~cm}^{-1}$, relating to the O-H-type bond, can be attributed to the presence of moisture during the tests, since they were not carried out under an inert atmosphere.

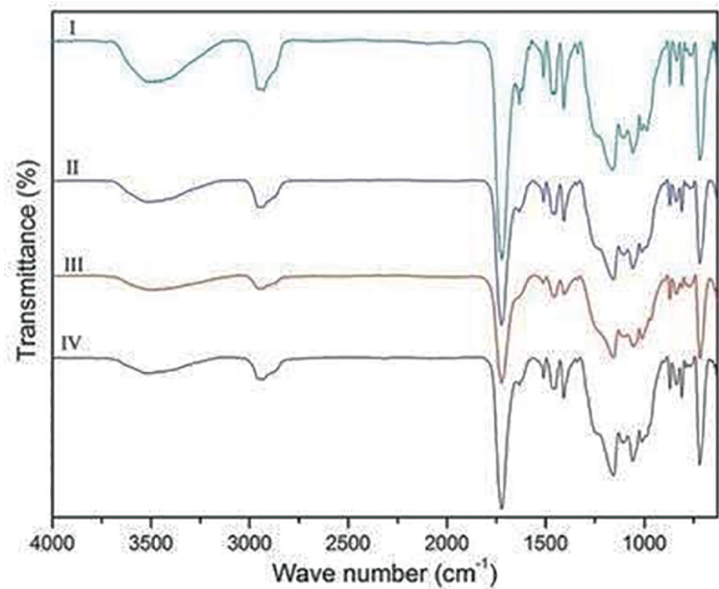

Figure 7. FTIR spectra of polymeric film for UV protection: I) not exposed; II) exposure in UV-A radiation chamber with cooling for $1000 \mathrm{~h}$; III) exposure in UV-A and UV-B radiation chambers without cooling for $1000 \mathrm{~h}$; IV) exposure in thermal chamber for $1000 \mathrm{~h}$.

On comparing the FTIR-HATR spectra (Figure 7) for the samples exposed to the test conditions and those not exposed, no changes, such as the appearance and/or shifting of bands, were observed, verifying the stability of the polymeric film ${ }^{23-25}$.

\subsubsection{UV-Visible spectroscopy}

The UV-Vis spectra obtained for the polymeric film for UV protection are shown in Figure 8. It was observed that in the visible region the transmission remained at approximately $90 \%$ up to around $402 \mathrm{~nm}$, and it rapidly decreased to close to $0 \%$ in the region of $360 \mathrm{~nm}$ to $200 \mathrm{~nm}$. Thus, the polymeric film blocks almost all the radiation in the UV region, verifying that its use in a sensor to protect the LC against $\mathrm{UV}$ radiation is appropriate. The curves did not show any change in the wavelengths or an increase/ decrease in intensity, suggesting that degradation processes did not take place under the conditions tested.

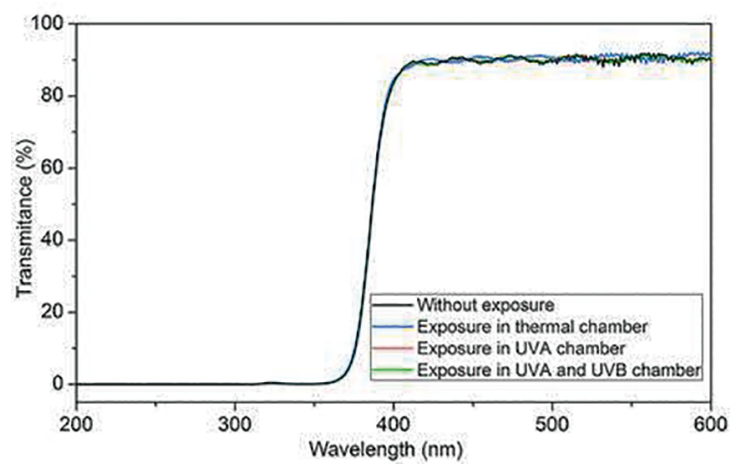

Figure 8. UV-Vis spectra for the polymeric film for UV protection without exposure and with exposure to the test conditions for $1000 \mathrm{~h}$. 
The results obtained in the FTIR-HATR and UV-Vis spectroscopy analysis of the polymeric film for UV protection indicated that this material could be used in the construction of a temperature sensor, with good durability and performance for use in the field.

\subsection{Temperature sensor}

The development of the temperature sensor prototype has been described above in the materials and methods section. The results for the evaluation of the color variation presented by the LC can be observed in Figure 9.
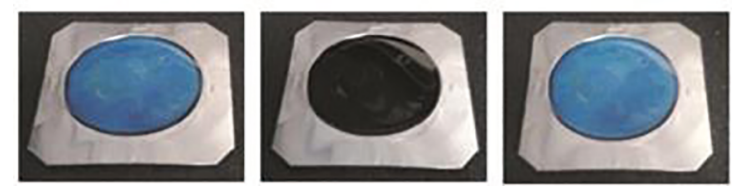

Figure 9. Color variation of $\mathrm{LC}$ in the temperature sensor prototype: on the left, heating from 80 to $90^{\circ} \mathrm{C}$; in the center, isotropic phase at temperatures above $100^{\circ} \mathrm{C}$; on the right, cooling from 90 to $80^{\circ} \mathrm{C}$.

It was observed during the heating process that at $80^{\circ} \mathrm{C}$ and with the formation of mesophase the LC displayed a blue color, which remained up to $90{ }^{\circ} \mathrm{C}$. As the heating process continued, fusion occurred and the LC became colorless, which allowed the black color applied to the bottom of the cavity to be observed. Thus, the sensor can be used to identify two temperature conditions $\left(\sim 80\right.$ and $\left.>100{ }^{\circ} \mathrm{C}\right)$.

This evaluation was also carried out for the temperature sensor prototypes exposed to the test conditions for $1000 \mathrm{~h}$ and the color changes observed were the same as those for the prototype without exposure shown in Figure 9. Thus, it was verified that the exposure of the prototypes to the tested conditions did not alter the desired characteristic (i.e., the change in color), demonstrating the good stability of the LC when applied as a temperature sensor.

The stability of the blue color of the LC in the temperature sensor prototype exposed to the thermal chamber was monitored daily and it was verified that this condition remained unchanged for the whole exposure time. This result indicates that the temperature sensor with LC offers good stability for the identification of hot spots in connectors, its color characteristics being the main feature of interest. The results with regard to the functionality of the temperature sensor under simulated working conditions are given in Figure 10.

The temperature sensor developed in this study demonstrated the behavior expected during the simulation of overheating in a wedge-type connector (Figure 10), with easy visualization of the color changes at certain temperatures. Field tests were performed with the developed devices, simulating the actual operating environment, and the hot spots can be easily identified during inspections without the need for the use of specialized equipment and/or personnel.

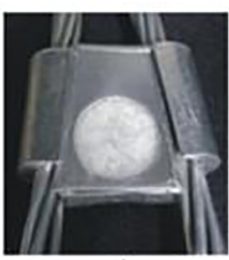

a)

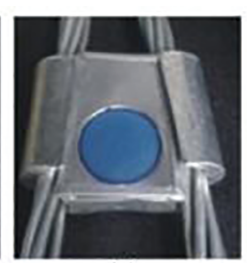

b)

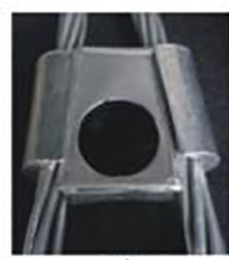

c)
Figure 10. Temperature sensor assembled in wedge-type connector: (a) at room temperature; (b) with heating and cooling between 80 and $90{ }^{\circ} \mathrm{C}$; (c) above $100{ }^{\circ} \mathrm{C}$.

\section{Conclusions}

The LC evaluated under artificial conditions in thermal and UV radiation chambers did not show significant alterations in terms of chemical structure or the color change feature. The evaluation of the protective polymeric film under the same test conditions also verified stability. Thus, these materials appear to be viable for the development of temperature sensors for use in the field.

Temperature sensor prototypes were prepared and subjected to UV and thermal degradation tests, and their behavior in terms of color change and stability was evaluated. The results demonstrated the stability of the sensor under the test conditions, since there was no change in the functional characteristics (color change) after the tests.

Other important factors are related to the conception of the temperature sensor. Besides being assembled without the need for specialized equipment and personnel, the aluminum plate used as the recipient base can be easily dimensioned, broadening the possibilities for the use of this sensor in other components of electrical systems which can show undesired overheating. The prototypes were sent for field monitoring on real connectors in the electric distribution network. These sensors, during an evaluation period of 90 days, indicated good performance on monitoring the overheating of these connectors. Based on the results obtained, the temperature sensor developed in this study is able to identify hot spots for long periods of time in service. Also, the easy color visualization is fundamental to accelerating the inspection of the components of electrical systems.

\section{Acknowledgements}

The authors would like to thank Centrais Elétricas de Santa Catarina S.A (CELESC P\&D) 5697-8712/2012 for their financial support.

\section{References}

1. Braunovic M, Myshkin NK, Konchits VV. Electrical Contacts: Fundamentals, Applications and Technology. Boca Raton: CRC Press; 2006. 672 p. 
2. CELESC - Centrais Elétricas de Santa Catarina S.A. Manual Especial: Conector cunha; 2006. Available from: <http:// novoportal.celesc.com.br/portal/index.php/normas-tecnicas/ especificacao-de-equipamentos-e-materiais $>$. Access in: 12/2/2014.

3. Pelizzari E, Martins COD, Menezes AFS. Aplicações da termografia como ferramenta de manutenção preditiva em conectores elétricos. In: $17^{\circ}$ Congresso Brasileiro de Engenharia e Ciência dos Materiais (CBECIMat); 2006 Nov 15-19; Foz do Iguaçu, PR, Brazil. p. 6315-6325.

4. Brasil. Agência Nacional de Energia Elétrica (ANEEL). Resolução $N^{o}$ 024: Estabelece as disposições relativas à continuidade da distribuição de energia elétrica às unidades consumidoras; 2000. Available from: <http://www.aneel.gov.br>. Access in: $12 / 2 / 2014$

5. Revie RW, ed. Uhlig's Corrosion Handbook. $3^{\text {rd }}$ ed. Hoboken: John Wiley \& Sons; 2011. 1296 p.

6. Lindquist TM, Bertling L, Eriksson R. Estimation of disconnector contact condition for modelling the effect of maintenance and ageing. In: Power Tech, 2005 IEEE Russia; 2005 June 25-30; St. Petersburg, Russia. IEE. p. 1-7.

7. Suesut T, Nunak N, Nunak T, Rotrugsa A, Tuppadung Y. Emissivity measurements on material and equipment in electrical distribution system. In: $11^{\text {th }}$ International Conference on Control, Automation and Systems; 2011 Oct 26-29; Gyeonggi-do, South Korea. IEEE. p. 1259-1263.

8. Braunovic M. Aluminium Connections: legacies of the past. In: Proceedings of the Fortieth IEEE Holm Conference on Electrical Contacts; 1994 Oct 17-19; Chicago, IL, USA. IEEE. p. 1-31.

9. Fu WH, Hsiao VKS, Tang JY, Wu MH, Chen Z. All fiberoptic sensing of light using side-polished fiber overlaid with photoresponsive liquid crystals. Sensors and Actuators B: Chemical. 2011;156(1):423-427.

10. Smith CR, Sabatino DR, Praisner TJ. Temperature sensing with thermochromic liquid crystals. Experiments in Fluids. 2001;30(2):190-201.

11. Brown TL. Química: a Ciência Central. 9a ed. São Paulo: Pearson Education; 2005. 992 p.

12. Algorri JF, Urruchi V, Bennis N, Sánchez-Pena JM, (2014) A Novel High-Sensitivity, Low-Power, Liquid Crystal Temperature Sensor, Sensors (Basel). 14(4): 6571-6583.
13. Heiney PA, Fontes E, de Jeu WH, Riera A, Carroll P, Smith AB. Frustration and helicity in the ordered phases of a discotic compound. Journal de Physique France. 1989;50(4):461-462.

14. Goodby JW. Phase Structures of calamitic liquid crystals. In: Demus D, Goodby J, Gray GW, Spiess HW, Vil V. Handbook of liquid crystals. Pt II. Weinheim: Wiley-VCH; 1998. p. 3-21.

15. Meier G, Sackmann E, Grabmaier JG. Applications of Liquid Crystals. Berlin Heidelberg: Springer-Verlag; 1975.

16. Moreira MF, Carvalho ICS, Cao W, Bailey C, Taheri B, PalffyMuhoray P. Cholesteric liquid-crystal laser as an optic fiber-based temperature sensor. Applied Physics Letters. 2004;85(14):2691.

17. EPAGRI. Dados históricos. 2015. Available from: <http://sol. ciram.sc.gov.br/siscrici/produtos/form_dadosHist.jsp?Dia1 $=2$ $0 \&$ Mes $1=4 \&$ Ano $1=2015 \&$ Dia $2=20 \& \bar{M}$ es $2=5 \&$ Ano $2=2015 \&$ estacao $=1043>$. Access in: 19/1/2015.

18. Frenkel M, Marsh KN. Spectral Data for Steroids. Boca Raton: CRC Press; 1994. 996 p.

19. Gao W, Schmoldt D, Slusser JR, eds. UV Radiation in Global Climate Change: Measurements, Modeling and Effects on Ecosystems. Berlin Heidelberg: Springer-Verlag; 2010.

20. Rånby B. Photodegradation and photo-oxidation of synthetic polymers. Journal of Analytical and Applied Pyrolysis. 1989;15:237-247.

21. Fragata F, Amorim CC, Ordine AP. Desempenho de tintas de acabamento frente às radiações ultravioleta, UVA e UVB, e condensação de umidade. Corrosão e Protecção de Materiais. 2010;29(3):91-98.

22. Nonemacher R, Santos P, Tomasi L, Santana FA, Evangelista M, Pires M, et al. Avaliação da aplicabilidade de técnicas MIC/ FT-IR/DSC para a caracterização de filmes multicamadas. Polímeros. 2007;17(2):158-168.

23. Holland BJ, Hay JN. The thermal degradation of PET and analogous polyesters measured by thermal analysis-Fourier transform infrared spectroscopy. Polymer. 2002;43(6):1835-1847.

24. Botelho G, Queirós A, Liberal S, Gijsman P. Studies on thermal and thermo-oxidative degradation of poly(ethylene terephthalate) and poly(butylene terephthalate). Polymer Degradation and Stability. 2001;74(1):39-48.

25. Bruno S, Zapponi M, Lazzarino HE, Pedraza JP. Metodología para Estimar la Resistencia al "Weathering" de Material Prepintado. Corrosão e Proteç̧ão de Materiais. 2008;27(2):40-46. 